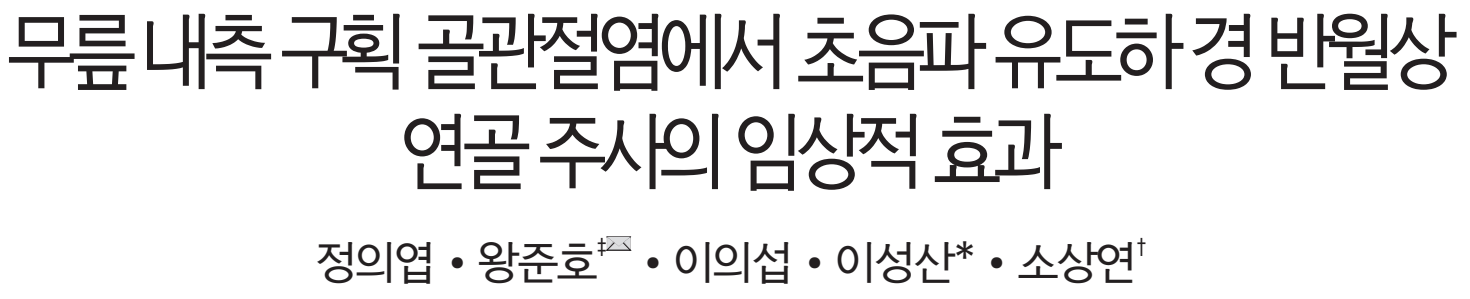

국립중앙의료원 정형외과, *인제대학교 의과대학 일산백병원 정형외과학교실, ${ }^{\dagger}$ 바른세상병원 정형외과, ${ }^{\ddagger}$ 성균관대학교 의과대학 삼성서울병원 정형외과학교실

\title{
Clinical Outcomes of Ultrasound-Guided Transmeniscal Injection in Medial Compartment Knee Osteoarthritis
}

\author{
Eui Yub Jung, M.D., Joon Ho Wang, M.D. ${ }^{\ddagger}$, Eui-Sub Lee, M.D., Sung-Sahn Lee, M.D.* ${ }^{\star}$, and Sang-Yeon So, M.D. ${ }^{\dagger}$ \\ Department of Orthopaedic Surgery, National Medical Center, Seoul, ${ }^{*}$ Department of Orthopaedic Surgery, Ilsan Paik Hospital, Inje University \\ College of Medicine, Goyang, ${ }^{\dagger}$ Department of Orthopaedic Surgery, Barunsesang Hospital, Seongnam, ${ }^{\dagger}$ Department of Orthopaedic Surgery, \\ Samsung Medical Center, Sungkyunkwan University School of Medicine, Seoul, Korea
}

Purpose: The purpose of this study was to introduce the ultrasound-guided transmeniscal injection in medial compartment knee osteoarthritis and analyze the clinical outcomes.

Materials and Methods: The electronic medical records of 36 patients with medial compartment knee osteoarthritis who were treated with an ultrasound-guided transmeniscal injection from March 2019 to July 2019 were accessed for this retrospective review. Using an ultrasound guided spinal needle, the patients received an intra-articular steroid injection at the medial compartment of the knee. A physical examination was conducted at the initial visit (pre-injection), and at one week, four weeks, and eight weeks after the injection. The numeric pain rating scale (NRS), Lequesne index, and Western Ontario and McMaster Universities Osteoarthritis (WOMAC) score were measured at each visit and analyzed over time. The percentage change of the patients who revealed substantial improvement was analyzed. The NRS, Lequesne index, and percentage of patients, who revealed substantial improvement over time classified by osteoarthritis grade, were analyzed.

Results: The NRS and Lequesne index decreased at one week, four weeks, and eight weeks after the injection compared to the initial baseline, and the pain-relief effect continued without change until eight weeks. The percentage of patients who showed substantial improvement at one, four, and eight weeks was 50.0\%, 47.2\%, and 52.8\%, respectively. The WOMAC scores decreased at one, four, and eight weeks compared to the initial baseline, and the decrease was continued without any difference until eight weeks. The percentage of patients with osteoarthritis stage 1 or 2 who revealed more than substantial improvement was significantly higher at one, four, and eight weeks than those with osteoarthritis stages 3 or 4 ( $p<0.05)$.

Conclusion: In patients with medial compartment knee osteoarthritis, the pain reduction and functional improvement persisted for at least eight weeks after the ultrasound-guided transmeniscal injection at the medial compartment. In particular, patients with medial compartment osteoarthritis stage 1 or 2 showed more effective pain reduction.

Key words: knee, osteoarthritis, ultrasound, injections

Received September 20, 2019 Revised November 4, 2019

Accepted November 18, 2019

Correspondence to: Joon Ho Wang, M.D.

Department of Orthopaedic Surgery, Samsung Medical Center, 81 Irwon-ro, Gangnam-gu, Seoul 06351, Korea

TEL: +82-3410-3507 FAX:+82-3410-0061 E-mail: mdwang88@gmail.com

ORCID: https://orcid.org/0000-0001-6530-795X

\section{서 론}

무릎 골관절염 환자에서 생활 개선, 휴식, 약물 치료 등에도 불구 하고 통증 호전을 보이지 않는 경우, 관절강내 corticosteroid 주 사는 단기간 동안 환자에게 통증 감소와 생활개선을 주는 것으로 
알려져 있다. ${ }^{1-3)}$ 일반적으로 corticosteroid 주사는 상슬개낭에 시행하게 되는데, 이는 삼출액을 뽑기가 쉽고 대퇴골과 경골에 방해를 받지 않으며 무릎 관절강내는 모두 연결되어 있기 때문에 병변이 있는 곳까지 그 효과가 미치기 때문이다. ${ }^{4)}$

하지만 무릎 관절강내에 흔히 사용하는 corticosteroid는 녹는 제제로 관절 내 활액막의 혈관과 림프관을 통해서 빠르게 흡수된 다. 때문에 주사 후 관절강내 원하는 곳까지 도달하기 전에 많은 부분이 흡수되어 버릴 수 있다.5,6) 따라서 최근 연구들은 무릎 내 병변에 직접 주사하려는 시도를 하고 있으며 원하는 위치에 주사 하기 위해서 실시간으로 해부학적 구조물을 확인할 수 있고, 간 편하고, 방사선 노출이 없는 초음파를 이용하고 있다. ${ }^{7-9)}$

무릎의 골관절염은 생역학적 이유로 인하여 내측 구획에 호발 한다고 알려져 있으며, 이로 인해서 주로 내측 통증이 많이 발생 한다. ${ }^{10)}$ 따라서 저자는 무릎 내측 구획 골관절염이 있는 환자들에 서 내측 구획에 corticosteroid 주사를 하면 좋은 결과를 보일 것 이라는 가설을 세웠다. 본 연구의 목적은 무릎 관절염이 가장 흔 하게 발생하는 내측 구획에 초음파 유도하 경 반월상 연골 corticosteroid 주사를 시행한 임상적 결과에 대해서 분석하는 것이 다.

\section{대상및 방법}

\section{1. 연구 대상}

본 연구는 국립중앙의료원 생명윤리심의위원회의 승인을 받고 시행되었다(H-1908-105-002). 2019년 3월부터 2019년 7월까 지 외래로 내원하여 초음파 유도하 무릎 내측 구획에 경 반월상 연골 주사를 맞은 36 명의 환자를 대상으로 후향적으로 분석하였 다. 환자 포함 기준은 1) 3 개월 이상 약물치료에도 호전이 없고, 2) X-ray상에서 내측 구획의 골관절염 소견이 관찰되며, 3) 신체 진찰상 내측 관절선 동통이 관찰되며, 4) 무릎 내측 부위에 피부 병변이 없는 환자였다. 환자 제외 기준은 1) 골관절염이 외측 구 획 또는 슬개-대퇴관절에만 국한된 경우, 2) 신체진찰상 관절운
동범위 전반에서 통증을 보이는 경우, 3) 추시 중 무릎 수술을 받 은 경우, 4) 추시 중 타병원에서 주사치료나 약물치료를 추가로 받은 환자, 5) 동시에 양측 주사를 받은 환자, 6) 8주 이상 추시가 되지 않은 경우였다(Fig. 1). 연구 대상의 평균 추시 기간은 11.5 주(8-16주), 나이는 64.58세(47-83세), 남성 16명, 여성 20명, 우측 20 예, 좌측 16 예였다.

\section{2. 무릎 내측 구획의 초음파 유도하 경 반월상 연골 주사 소개} 주사 약제는 triamcinolone $40 \mathrm{mg} / \mathrm{ml} 1 \mathrm{ml}, 7.5 \%$ ropivacaine $1 \mathrm{ml}$ 를 섞어 총 $2 \mathrm{ml}$ 를 $3 \mathrm{ml}$ 주사기에 넣어 사용하였으며, 피부 마취를 위해서 $2 \%$ lidocaine $3 \mathrm{ml}$ 를 사용하였다. 약제 삽입 을 위한 척추 바늘은 22 게이지를 사용하였다. 먼저 환자를 시술 자를 보도록 하여 측와위 자세로 위치시킨 후 환측 무릎의 내측 이 위를 향하게 한 상태에서 무릎을 약간 굴곡시켰다. 반대측 다 리는 주사 시에 시술자에게 방해가 될 수 있으므로 개구리 다리 자세를 하여 외전시켜놓았다. 피부 표면에 미리 대퇴내과와 경골 의 선을 그어놓아 탐색자의 위치를 대략 가늠해 놓고 피부 소독 전 미리 관절선에 대해서 장축과 단축 영상을 확인하였다(Fig. 2).

$10 \%$ povidone-iodine으로 먼저 피부 소독을 한 후 5\% chlorhexidine gluconate으로 소독을 한 후 구멍 뚫린 포를 병변 이 가운데 위치하도록 하였다. 먼저 관절선에 대한 단축 영상이 가운데 오도록 탐색자를 위치시킨 후 바늘을 정 중앙으로 오도록 하여 피부 마취를 시행하였다. 이때 바늘은 실제 척추 바늘이 지 나가야 하는 주행과 일치하는 것이 좋으며, 내측 측부 인대를 가 능한 한 피해서 들어가야 통증이 적으므로 대퇴내과와 경골이 만 나는 지점보다 앞쪽에서 삽입하는 것이 좋다. 척추 바늘은 관절 선에 대한 out of plane 술기로 삽입하였으며, 내측 반월상 연골 판의 가운데로 지나감을 확인한 후 탐색자를 90 도 회전시켜 in plane 술기로 척추 바늘의 각도를 확인하며 내측 구획으로 진행 함을 확인하였다. 이때 시술자는 처음 연골판을 지나갈 때는 약 간의 저항이 느껴지고 이것이 내측 구획으로 들어갈 때는 갑자기 저항이 사라지는 느낌을 받아야 한다. 척추 바늘의 끝이 적절하

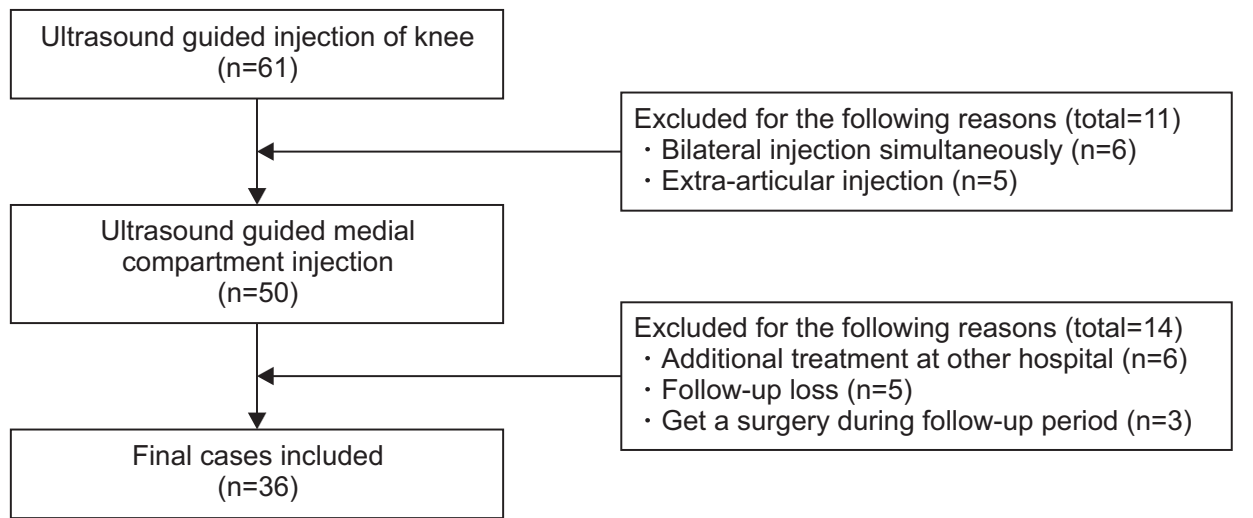

Figure 1. The flowchart shows patient selection and exclusion criteria. 
Eui Yub Jung, et al.

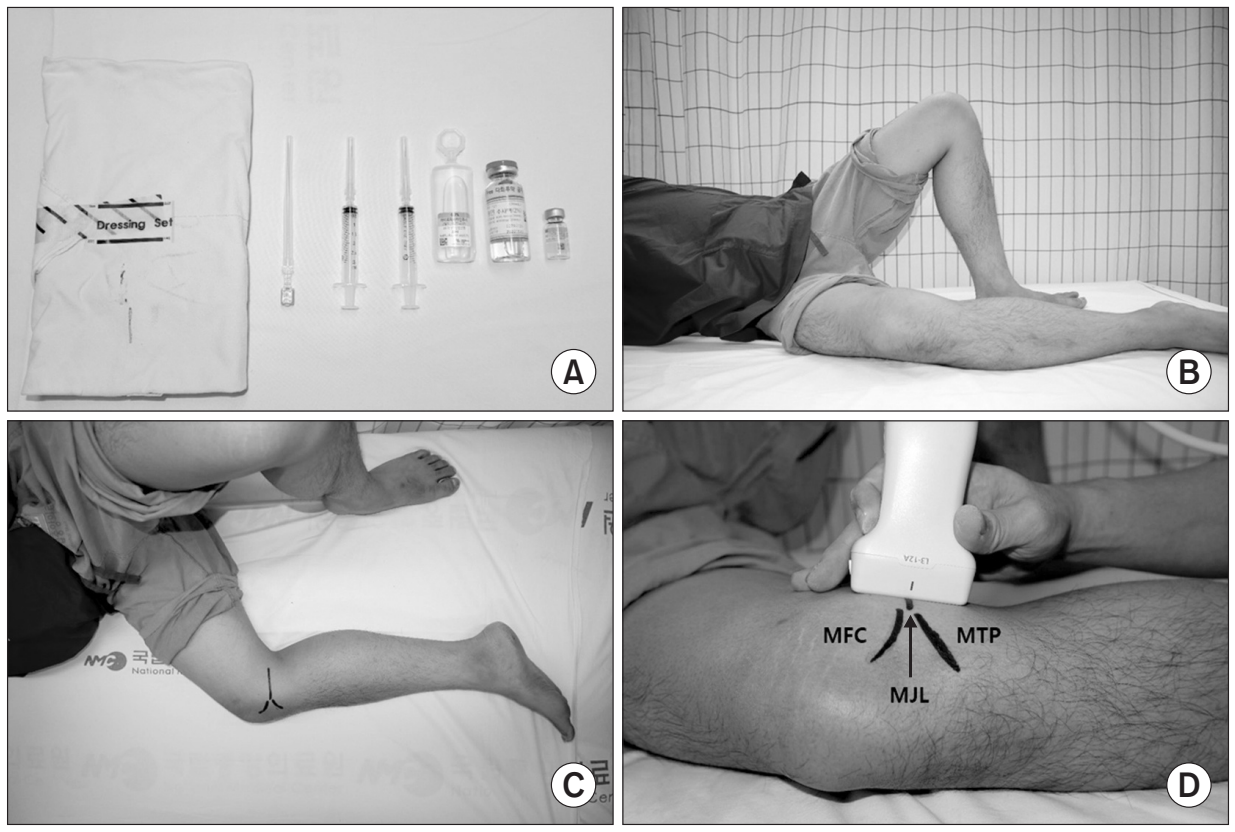

Figure 2. (A) Dressing set, spinal needle (22G), $3 \mathrm{ml}$ syringe (2 ea), 7.5\% ropivacaine $1 \mathrm{ml}, 2 \%$ lidocaine $3 \mathrm{ml}$, triamcinolone 40 $\mathrm{mg} / \mathrm{ml} 1 \mathrm{ml}$ were prepared for injection. (B) With the patient in the lazy lateral decubitus facing the operator, the patient's leg was placed in a side-lying position with the target side (medial side) of the knee (with $30^{\circ}-45^{\circ}$ flexion) facing the ceiling while the other knee was flexed and externally rotated. (C) The medial femoral condyle and Medial tibia plateau line were marked on the skin surface. (D) Check the long axis view and the short axis view of the medial Joint Line sonographically prior to draping the injection site. MFC, medial femoral condyle; MTP, medial tibia plateau; MJL, medial joint line.
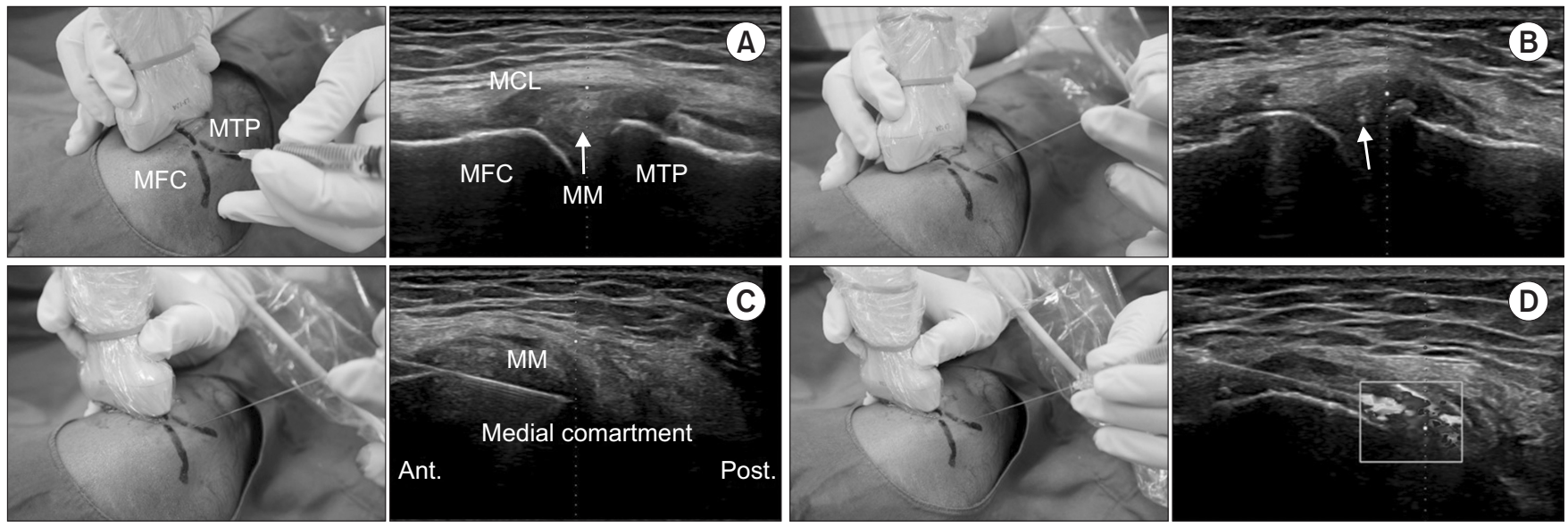

Figure 3. (A) Skin was anesthetized with $2 \%$ lidocaine by positioning the needle in the middle of the short axis view of the medial joint line. To avoid MCL, the needle was inserted Ant. to the point where the MFC meets the tibia plateau. The arrow points to the MM. (B) For the mid-line of the MM, a spinal needle was advanced using an out-of-plane approach (white arrow: tip of the spinal needle). (C) Once the needle tip was visualized within the meniscal body, the transducer was rotated $90^{\circ}$ into the long axis of the medial joint line, yielding an in-plane view of the needle. The needle was advanced to the medial compartment using an in-plane approach. (D) After final needle tip placement, the operator injected the mixed drug (7.5\% ropivacaine $1 \mathrm{ml}$, triamcinolone $40 \mathrm{mg} / \mathrm{ml} 1 \mathrm{ml}$ ). The drug's administration was confirmed by visualizing the Doppler image. MCL, medial collateral ligament; MFC, medial femoral condyle; MTP, medial tibia plateau; MM, medial meniscus, Ant., anterior; Post., posterior.

게 내측 구획으로 위치시켰다면 도플러 영상을 확인하면서 주사 약제를 주입한다(Fig. 3).

\section{3. 임상적 결과 평가}

무릎의 골관절염의 정도는 Kellgren-Lawrence (K-L) 단계를 사 용하여 측정하였다. ${ }^{11)}$ 주사 전과 1 주, 4 주, 8 주째 numeric pain rating scale (NRS), Lequesne index (0-8점), ${ }^{12)}$ Western On- tario and McMaster Universities Osteoarthritis Index (WO$\mathrm{MAC}$ ) 점수를 측정하였다. 주사 전을 기준으로 1 주, 4 주, 8 주째 NRS 변화량과 Lequesne index 변화량을 측정하였다. The Initiative on Methods, Measurement, and Pain Assessment in Clinical Trials (IMMPACT) 권고를 기준으로 NRS의 50\% 이상 감소가 있었던 환자들의 비율을 “상당한 호전이 있었던 환자들의 비율"로 정의하였고, ${ }^{13,14)}$ 이를 1 주, 4 주, 8 주째 확인하였다. $\mathrm{K}-\mathrm{L}$ 
1, 2단계와 3, 4단계를 나누어 1주, 4주, 8주째 NRS, Lequesne index 차이를 확인하였으며 상당한 호전이 있었던 환자들의 비 율을 확인하였다.

\section{4. 통계 분석}

전체 환자의 NRS, Lequesne index, WOMAC 점수는 기술적 통계를 시행하여 평균값과 표준편차를 구하였다. 시간에 따른 NRS, Lequesne index, WOMAC 점수 차이는 먼저 정규분포 여 부를 Kolmogorov-Smirnov 검정과 Shapiro-Wilk 검정을 시 행한 후 정규분포를 갖는 경우에는 대응표본 t검정을 시행하였고 그렇지 않은 경우에는 Mann-Whitney 검정을 시행하였다. 시간 에 따른 상당한 호전이 있었던 환자들의 비율 차이는 McNemar 검정을 시행하였다. $\mathrm{K}-\mathrm{L}$ 단계와 신체진찰에 따른 두 군 간의 비 교는 연속변수인 경우 정규분포를 갖는 경우에는 독립표본 $\mathrm{t}$ 검정 을 시행하였고 그렇지 않은 경우 Mann-Whitney 검정을 시행하 였다. 상당한 호전이 있었던 환자들의 두 군 간의 비율 차이는 각
항목당 빈도가 5 미만인 경우가 전체 항목의 $20 \%$ 이상이 된다면 Fisher 검정을 시행하였고 그렇지 않다면 chi-squared 검정을 시행하였다. 모든 통계 수치는 양측 검정을 하였으며 유의확률 이 0.05 미만인 경우를 통계적으로 의미가 있다고 하였다. 통계 분석은 PASW statistics ver. 18.0 (IBM Corp., Armonk, NY, USA)을 사용하였다.

\section{결 과}

내측 구획의 골관절염 정도는 K-L 1단계 16 명, 2 단계 7 명, 3 단 계 5명, 4단계 8명이었다. 주사 전 NRS는 6.1 \pm 1.8 점, Lequesne

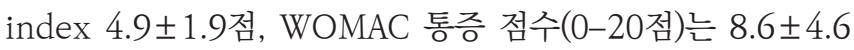

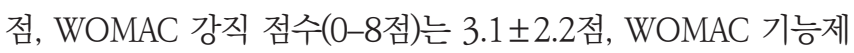

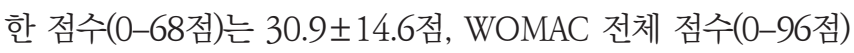

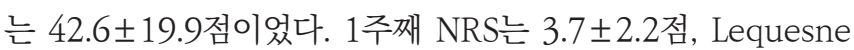
index $3.0 \pm 1$.8점, WOMAC 통증 점수는 $5.3 \pm 3$.8점, 강직 점수

Table 1. Change of Clinical Parameters over Time

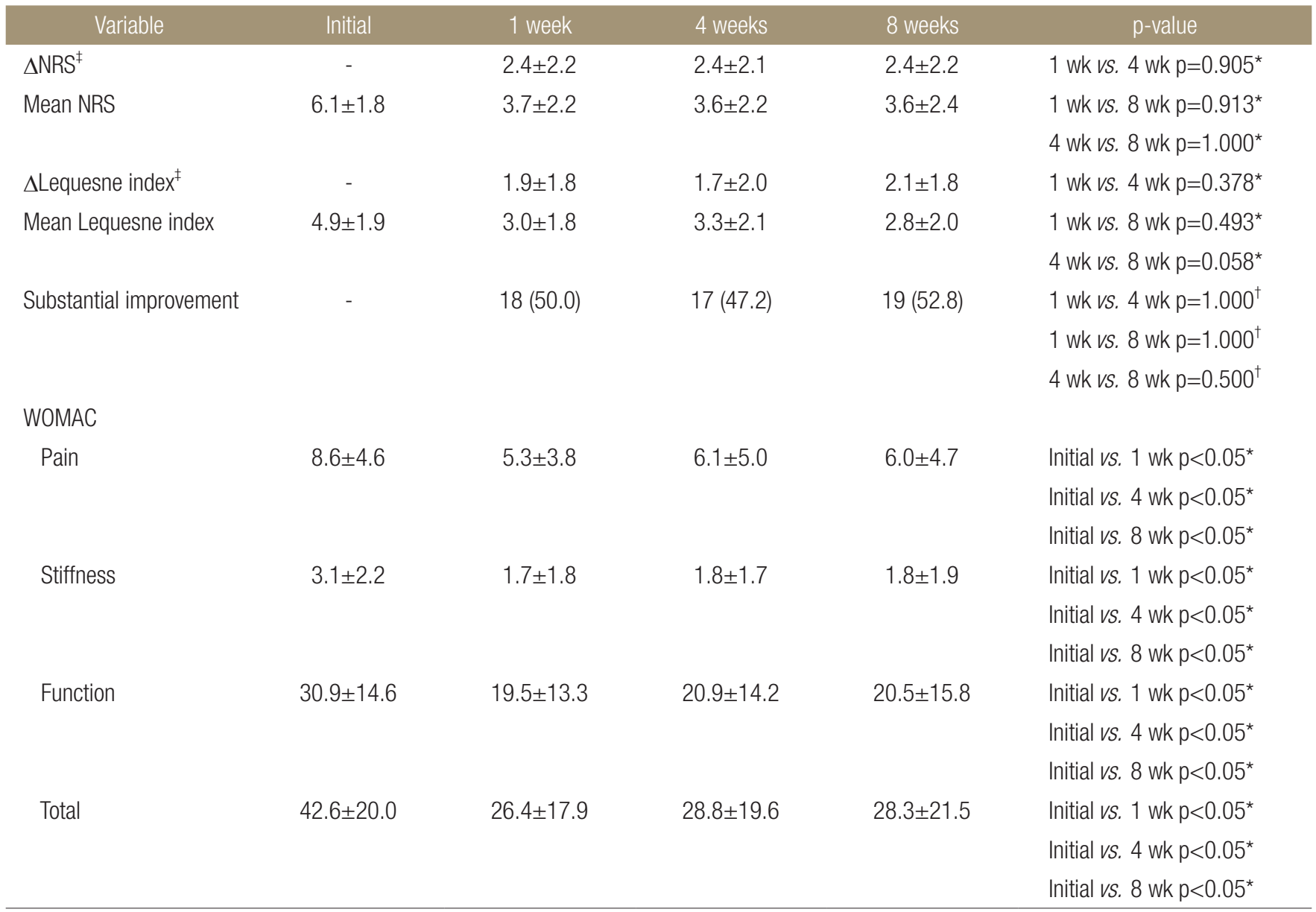

Values are presented as mean \pm standard deviation or number (\%). ${ }^{*}$ Paired t-test. ${ }^{\dagger}$ McNemar test. ${ }^{\ddagger}$ The change of parameters from the initial baseline (positive when parameters at later visit decreased). NRS, numeric pain rating scale; WOMAC, Western Ontario and McMaster Universities Osteoarthritis; -, not available. 
Eui Yub Jung, et al.

$1.7 \pm 1.8$ 점, 기능제한 점수 $19.5 \pm 13.3$ 점, 전체 점수 $26.4 \pm 17.9$

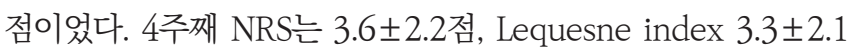
점, $\mathrm{WOMAC}$ 통증 점수는 $6.1 \pm 5.0$ 점, 강직 점수 $1.8 \pm 1.7$ 점, 기 능제한 점수 $20.9 \pm 14.1$ 점, 전체 점수 $28.8 \pm 19$.6점이었다. 8주

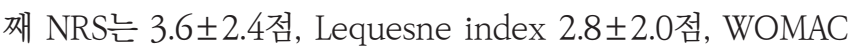
통증 점수는 $6.0 \pm 4.7$ 점, 강직 점수 $1.8 \pm 1.9$ 점, 기능제한 점수 $20.5 \pm 15.8$ 점, 전체 점수 $28.3 \pm 21.5$ 점이었다(Table 1).

주사 전과 비교하여 1 주 후 NRS는 2.4 \pm 2 .2점 감소, $\mathrm{Le}-$ quesne index $1.9 \pm 1.8$ 점 감소하였다. 상당한 호전이 있었던 환 자들의 비율은 $50.0 \%$ (18/36명)였다. 주사 전과 비교하여 4주

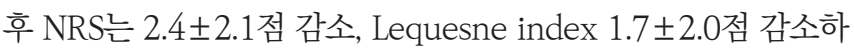
였다. 상당한 호전이 있었던 환자들의 비율은 47.2\% (17/36명) 였다. 주사 전과 비교하여 8주 후 NRS는 2.4 \pm 2 .2점 감소, Le-

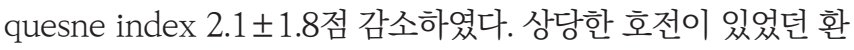
자들의 비율은 $52.8 \%(19 / 36$ 명)였다.

주사 전과 비교하여 1 주, 4 주, 8 주째 NRS 감소 정도의 차이 는 없었다(1주 vs. 4 주, $\mathrm{p}=0.905$; 1 주 vs. 8 주, $\mathrm{p}=0.913$; 4 주 vs. 8 주, $\mathrm{p}=1.000)$. 주사 전과 비교하여 1 주, 4 주, 8 주째 Lequesne index 감소 정도의 차이는 없었다(1주 vs. 4 주, $\mathrm{p}=0.378 ; 1$ 주 vs. 8주, p=0.493; 4주 vs. 8주, p=0.058). 1, 4, 8주째 WOMAC 통 증 점수, 강직 점수, 기능제한 점수, 전체 점수 모두 주사 전 보다

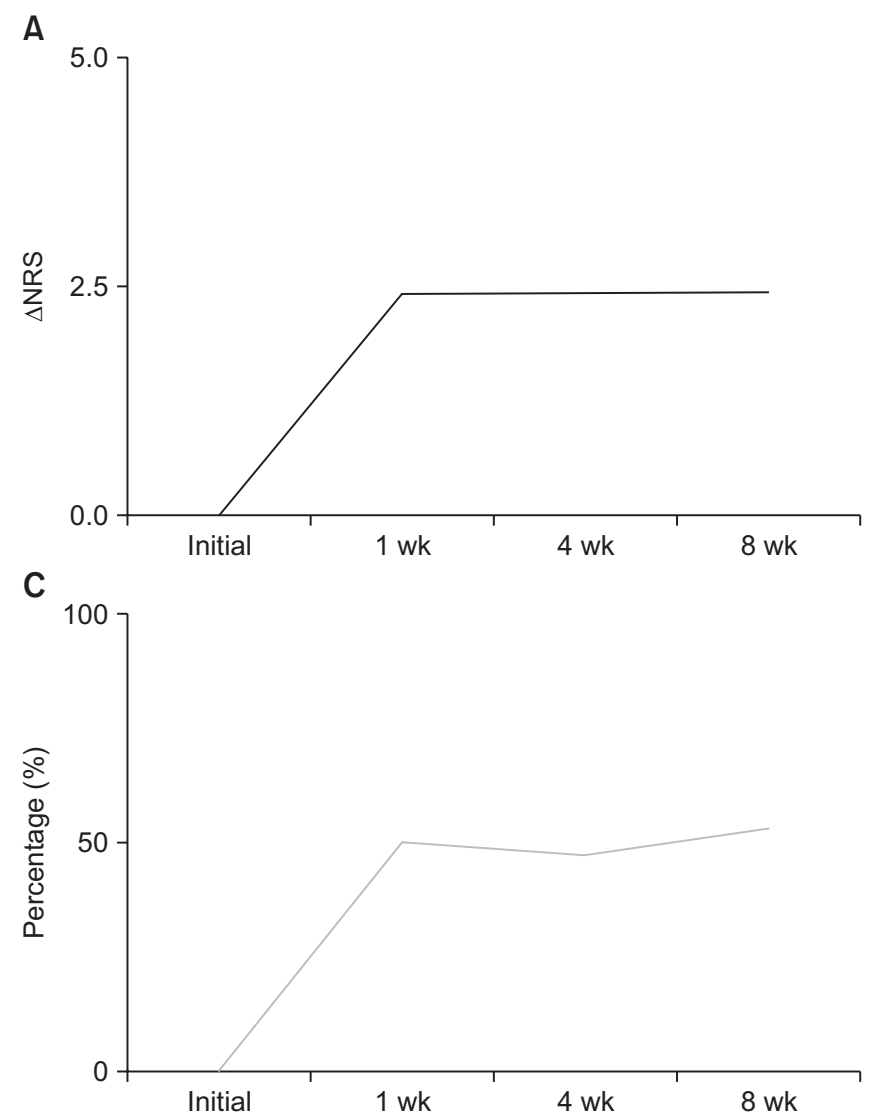

감소되었다 $(\mathrm{p}<0.05) .1$ 주, 4 주, 8 주째 상당한 호전이 있었던 환 자들의 비율은 차이가 없었다(1주 vs. 4주, $\mathrm{p}=1.000 ; 1$ 주 vs. 8 주, p=1.000; 4주 vs. 8주, p=0.500) (Fig. 4).

$\mathrm{K}-\mathrm{L} 1,2$ 단계 환자와 3 , 4단계 환자의 1 주, 4 주, 8 주째 NRS, Lequesne index 감소 차이는 없었으며 상당한 호전이 있었던 환자들의 비율은 K-L 1, 2단계 환자에서 유의하게 많았다(1주: $\mathrm{p}=0.015$, odds ratio $[\mathrm{OR}]=6.250 ; 4$ 주: $\mathrm{p}=0.041, \mathrm{OR}=5.185 ; 8$ 주: $\mathrm{p}=0.038, \mathrm{OR}=5.143$ ) (Table 2, Fig. 5).

\section{고 찰}

무릎 내측 구획 골관절염 환자에서 초음파 유도하 내측 구획에 대한 경 반월상 연골 주사는 1주, 4 주, 8 주까지 통증 감소 및 기 능 개선의 효과가 지속되었다. 특히, 내측 구획 골관절염 1,2 단 계의 환자에서는 3,4 단계의 환자보다 통증 감소 효과가 더 컸다.

본 연구에서는 무릎 내측 구획 골관절염 환자에서 초음파 유 도하 무릎 내측 구획에 경 반월상 연골 corticosteroid 주사 이후 평균 8주 이상의 통증 감소 효과를 확인하였다. Arroll과 Goodyear-Smith ${ }^{15)}$ 는 무릎 관절강내 corticosteroid 주사의 효과에 대한 10 개의 무작위 비교연구를 메타분석하였고, 대부분 2 주정 도까지의 단기간의 증상 개선을 보였으며 관절경적 세척술을 동

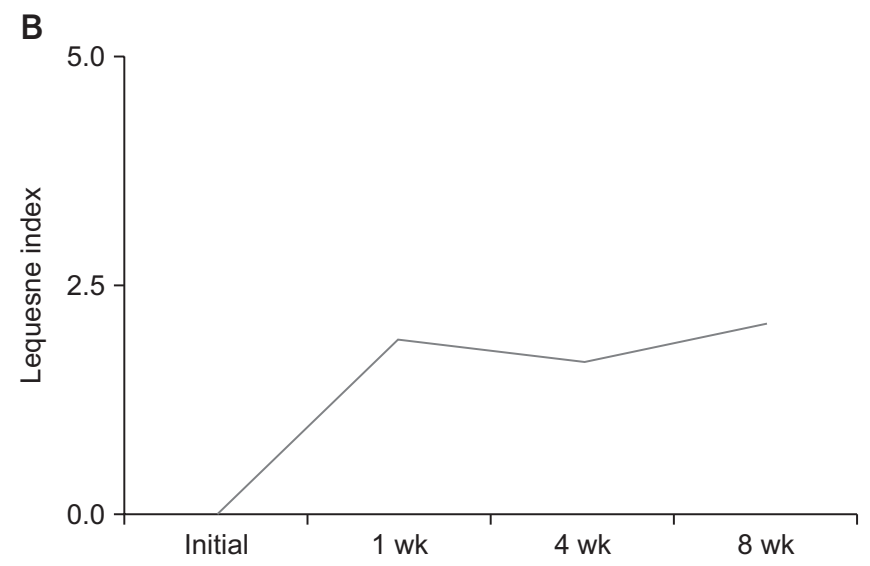

Figure 4. (A) $\triangle N R S$ changes over time. (B) The graph shows $\Delta$ Lequesne index change over time. (C) The graph shows the percentage change of patients who showed substantial improvement over time. NRS, numeric pain rating scale. 
Ultrasound-Guided Transmeniscal Injection

Table 2. Comparison of Clinical Parameters over Time by 0steoarthritis Grade

\begin{tabular}{|c|c|c|c|}
\hline Variable & $\begin{array}{c}\text { K-L 1, } 2 \\
(n=23)\end{array}$ & $\begin{array}{c}\text { K-L 3, } 4 \\
(n=13)\end{array}$ & $p$-value \\
\hline \multicolumn{4}{|l|}{$\Delta \mathrm{NRS}^{\S}$} \\
\hline 1 wk & $2.9 \pm 2.1$ & $1.6 \pm 2.3$ & $p=0.131^{*}$ \\
\hline 4 wk & $2.7 \pm 2.0$ & $2.0 \pm 2.1$ & $p=0.328^{*}$ \\
\hline $8 w k$ & $2.8 \pm 2.1$ & $1.9 \pm 2.5$ & $p=0.267^{\star}$ \\
\hline \multicolumn{4}{|l|}{$\Delta$ Lequesne index ${ }^{\S}$} \\
\hline 1 wk & $2.0 \pm 1.7$ & $1.9 \pm 2.0$ & $p=0.649^{\star}$ \\
\hline 4 wk & $1.7 \pm 2.1$ & $1.6 \pm 2.1$ & $p=0.537^{\star}$ \\
\hline 8 wk & $2.1 \pm 1.7$ & $2.0 \pm 2.0$ & $p=0.770^{\star}$ \\
\hline \multicolumn{4}{|c|}{ Substantial improvement } \\
\hline 1 wk & $15(65.2)$ & $3(23.1)$ & $\mathrm{p}<0.05^{\dagger}, \mathrm{OR}=6.250$ \\
\hline 4 wk & $14(60.9)$ & $3(23.1)$ & $\mathrm{p}<0.05^{\ddagger}, \mathrm{OR}=5.185$ \\
\hline $8 w k$ & $16(69.6)$ & $4(30.8)$ & $\mathrm{p}<0.05^{\ddagger}, \mathrm{OR}=5.143$ \\
\hline
\end{tabular}

Values are presented as mean \pm standard deviation or number (\%). ${ }^{*}$ Mann-Whitney U-test. ${ }^{\dagger}$ Chi-squared test. ${ }^{\ddagger}$ Fisher's exact test. ${ }^{\S}$ The change of parameters from the initial baseline (positive when parameters at later visit decreased). K-L, Kellgren-Lawrence; NRS, numeric pain rating scale; $\mathrm{OR}$, odds ratio.

반하거나 ${ }^{16)} 3$ 개월마다 지속적으로 주사를 한 경우 ${ }^{17)}$ 에 16-24개 월까지도 증상 개선을 보일 수 있다고 하였다. 이러한 연구 결과 들을 감안했을 때 본 연구에서 1 회 주사는 비교적 긴 통증 감소 효과를 갖는다. Wilderman 등은 내측 반월상 연골판 파열이나 퇴행성 변화가 있을 때 일반적인 상슬개골낭 주사나 하슬개골낭 주사 등은 효과가 떨어진다고 하였고 이는 병변이 위치해있는 내 측 구획까지 주사제가 도달하기 전 흡수되기 때문일 수 있다고 하였다. 저자 또한 본 연구에서 비교적 긴 통증 감소 효과를 보인 것은 무릎 관절염이 주로 발생하는 내측 구획에 초음파를 이용하 여 직접, 정확히 주사해 주사제의 이동거리가 짧아지고 상대적으 로 많은 양의 주사제가 병변 주변부의 구조물에 흡수되었기 때문 이라고 생각한다.

본 연구에서는 내측 구획 골관절염 1,2 단계 환자에서 1 주, 4 주, 8주 모든 기간 동안 상당한 호전이 있었던 환자들의 비율이 골관절염 3, 4단계 환자보다 많았다. 이러한 결과는 기존의 연구 결과들과 일치하는 결과이다. ${ }^{16,18)}$ Matzkin 등 ${ }^{19)}$ 은 무릎 골관절염 이 진행된 경우 통증의 원인이 해부학적 변형과 관련이 깊고 만 성 통증으로 인한 중추 신경계의 감작과 관련이 있을 수 있다고 하여 관절강내 corticosteroid 주사에 의한 항염증 효과는 초기 골관절염보다는 적다고 기술하고 있다. 관절강내 corticosteroid 주사는 주로 활액막의 항염증 작용을 하는 것으로 알려져 있고 골관절염의 통증의 원인은 활액막 이외에도 연골하골, 골막, 관

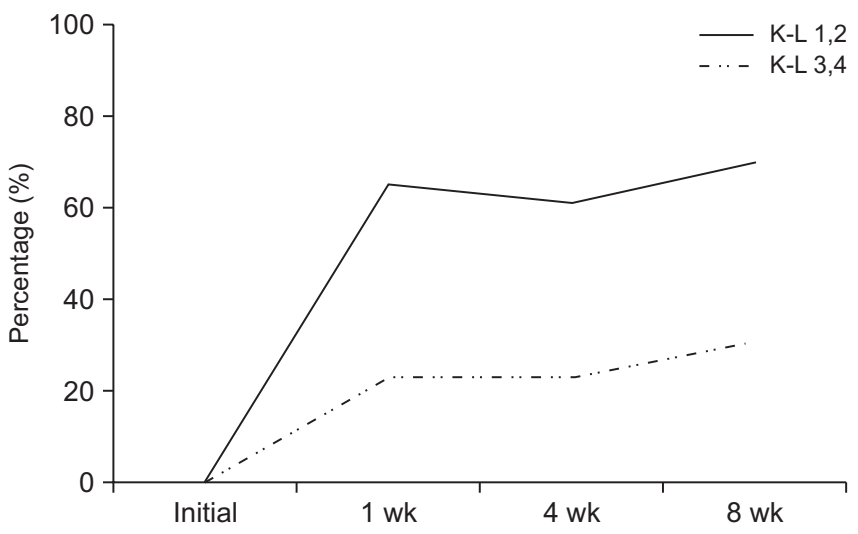

Figure 5. Percentage change of patients who revealed substantial improvement over time classified by osteoarthritis grade (KellgrenLawrence [K-L]).

절 주변 인대 및 근육에 의한 것이기도 하기 때문에 진행된 골관 절염의 경우 관절강내 corticosteroid 주사의 효과가 상대적으로 덜 효과적일 수 있다. ${ }^{17,20)}$

본 연구의 제한점은 첫째, 추시기간이 평균 8 주로 비교적 짧아 이후 지속 효과에 대해서 확인하지 못했다는 것이다. 저자는 일 반적으로 단독적으로 사용하는 1 회의 무릎 관절강내 corticosteroid 주사의 효과가 2주를 넘기 힘들다는 점을 감안했을 때 충분 하지는 않지만 지속성을 검증할 수 있다고 판단하였지만, ${ }^{15-17)}$ 추 후 추시기간을 늘려 통증 감소 효과가 떨어지는 시점을 확인하는 연구가 필요하다고 생각한다. 둘째, 후향적 연구였다는 점이다. 흔히 사용되고 있지 않은 임상적 방법을 이와 같이 최근, 단기간 에 후향적으로 분석했다는 것은 저자 개인의 주관이 개입될 가능 성이 높다고 생각한다. 추후 본 연구의 임상적 결과가 충분히 입 증된 후 전향적 분석을 통해서 보다 정확하고 신뢰성 있는 연구 가 필요할 것이다. 셋째, 비교 연구가 아니라는 점이다. 추후 일반 적으로 행해지는 관절강내 주사 방법과 비교 연구가 이루어져야 그 효과를 명확히 할 수 있을 것이다. 넷째, 연구 대상의 수가 적 다는 점이다. 특히, 내측 골관절염의 단계별 비교는 일부만 통계 적으로 의미가 있고 대부분의 변수에서는 차이가 있는 경향을 보 였으므로 추후 연구 대상을 늘린다면 좀 더 명확한 결과를 얻을 수 있을 것이다.

\section{결 론}

무릎 내측 구획 골관절염 환자에서 초음파 유도하에 관절강내 경 반월상 연골 주사는 통증 감소 및 기능 개선의 효과를 보였으며 그 효과는 평균 8주 이상 지속됨을 확인할 수 있었다. 특히, 초기 내측 구획 골관절염 환자를 선택적으로 주사한다면 더 큰 통증 감소 효과를 기대할 수 있을 것이다. 
Eui Yub Jung, et al.

\section{CONFLICTS OF INTEREST}

The authors have nothing to disclose.

\section{ORCID}

Eui Yub Jung, https://orcid.org/0000-0001-8108-6894

Joon Ho Wang, https://orcid.org/0000-0001-6530-795X

Eui-Sub Lee, https://orcid.org/0000-0002-4323-4689

Sung-Sahn Lee, https://orcid.org/0000-0001-7728-0061

Sang-Yeon So, https://orcid.org/0000-0002-0504-4411

\section{REFERENCES}

1. Bannuru RR, Natov NS, Obadan IE, Price LL, Schmid CH, McAlindon TE. Therapeutic trajectory of hyaluronic acid versus corticosteroids in the treatment of knee osteoarthritis: a systematic review and meta-analysis. Arthritis Rheum. 2009;61:1704-11.

2. Bellamy N, Campbell J, Robinson V, Gee T, Bourne R, Wells G. Intraarticular corticosteroid for treatment of osteoarthritis of the knee. Cochrane Database Syst Rev. 2006;2:CD005328.

3. Zhang W, Nuki G, Moskowitz RW, et al. OARSI recommendations for the management of hip and knee osteoarthritis: part III: changes in evidence following systematic cumulative update of research published through January 2009. Osteoarthritis Cartilage. 2010;18:476-99.

4. Jackson DW, Evans NA, Thomas BM. Accuracy of needle placement into the intra-articular space of the knee. J Bone Joint Surg Am. 2002;84:1522-7.

5. Wilderman I, Berkovich R, Meaney C, Kleiner O, Perelman V. Meniscus-targeted injections for chronic knee pain due to meniscal tears or degenerative fraying: a retrospective study. J Ultrasound Med. 2019;38:2853-9.

6. Larsen C, Ostergaard J, Larsen SW, et al. Intra-articular depot formulation principles: role in the management of postoperative pain and arthritic disorders. J Pharm Sci. 2008;97:462254.

7. Im SH, Lee SC, Park YB, Cho SR, Kim JC. Feasibility of sonography for intra-articular injections in the knee through a medial patellar portal. J Ultrasound Med. 2009;28:1465-70.

8. Luc M, Pham T, Chagnaud C, Lafforgue P, Legré V. Placement of intra-articular injection verified by the backflow technique. Osteoarthritis Cartilage. 2006;14:714-6.

9. Berkoff DJ, Miller LE, Block JE. Clinical utility of ultrasound guidance for intra-articular knee injections: a review. Clin Interv Aging. 2012;7:89-95.

10. Vincent KR, Conrad BP, Fregly BJ, Vincent HK. The pathophysiology of osteoarthritis: a mechanical perspective on the knee joint. PM R. 2012;4:S3-9.

11. Kellgren JH, Lawrence JS. Radiological assessment of osteo-arthrosis. Ann Rheum Dis. 1957;16:494-502.

12. Lequesne MG, Méry C, Samson M, Marty M. Comparison between the WOMAC and the Lequesne indices in patients with knee and hip osteoarthritis. Osteoarthritis Cartilage. 1998;6:441-2.

13. Dworkin RH, Turk DC, Farrar JT, et al. Core outcome measures for chronic pain clinical trials: IMMPACT recommendations. Pain. 2005;113:9-19.

14. Dworkin RH, Turk DC, Wyrwich KW, et al. Interpreting the clinical importance of treatment outcomes in chronic pain clinical trials: IMMPACT recommendations. J Pain. 2008;9:105-21.

15. Arroll B, Goodyear-Smith F. Corticosteroid injections for osteoarthritis of the knee: meta-analysis. BMJ. 2004;328:869.

16. Smith MD, Wetherall M, Darby T, et al. A randomized placebo-controlled trial of arthroscopic lavage versus lavage plus intra-articular corticosteroids in the management of symptomatic osteoarthritis of the knee. Rheumatology (Oxford). 2003;42:1477-85.

17. Raynauld JP, Buckland-Wright C, Ward R, et al. Safety and efficacy of long-term intraarticular steroid injections in osteoarthritis of the knee: a randomized, double-blind, placebo-controlled trial. Arthritis Rheum. 2003;48:370-7.

18. Arden NK, Reading IC, Jordan KM, et al. A randomised controlled trial of tidal irrigation vs corticosteroid injection in knee osteoarthritis: the KIVIS Study. Osteoarthritis Cartilage. 2008;16:733-9.

19. Matzkin EG, Curry EJ, Kong Q, Rogers MJ, Henry M, Smith EL. Efficacy and treatment response of intra-articular corticosteroid injections in patients with symptomatic knee osteoarthritis. J Am Acad Orthop Surg. 2017;25:703-14.

20. Pelletier JP, Martel-Pelletier J, Cloutier JM, Woessner JF Jr. Proteoglycan-degrading acid metalloprotease activity in human osteoarthritic cartilage, and the effect of intraarticular steroid injections. Arthritis Rheum. 1987;30:541-8. 


\section{무릎내측 구획 골관절염에서 초음파 유도하경 반월상 연골 주시의 임상적 호과 정의엽・ 왕준호}

국립중앙의료원 정형외과, *인제대학교 의과대학 일산백병원 정형외과학교실, ${ }^{\dagger}$ 바른세상병원 정형외과, ‡성균관대학교 의과대학 삼성서울병원 정형외과학교실

목적: 무릎 내측 구획 골관절염 환자에서 초음파 유도하 무릎 관절강내 경 반월상 연골 주사를 소개하고 그 임상적 결과를 분석하 고자 하였다.

대상 및 방법: 2019년 3월부터 2019년 7월까지 3개월 이상 무릎 통증이 지속되었던 무릎 내측 구획 골관절염 환자 중 초음파 유 도하 경 반월상 연골 주사를 시행한 36명의 환자에 대해서 후향적으로 분석하였다. 초음파 유도하 척추 바늘을 이용하여 무릎 관절강내 내측 구획에 corticosteroid와 국소마취제를 주사하였다. 시술 전, 1 주, 4 주, 8 주째 신체진찰을 하였고 numeric pain rating scale (NRS), Lequesne index, Western Ontario and McMaster Universities Osteoarthritis (WOMAC) 점수를 측정하 였다. 시간에 따른 NRS, Lequesne index, WOMAC 점수를 분석하였으며 상당한 호전이 있었던 환자들의 비율을 분석하였다. 또 한 내측 구획 골관절염의 단계에 따른 NRS, Lequesne index, 상당한 호전이 있었던 환자들의 비율을 분석하였다.

결과: 시술 전과 비교하여 1주, 4주, 8주째 NRS와 Lequesne index는 감소하였고 8주째까지 통증 감소 효과는 차이 없이 지속되 었다. 상당한 호전이 있었던 환자들의 비율은 1 주, 4 주, 8 주째 각각 $50.0 \%, 47.2 \%, 52.8 \%$ 였으며 8주째까지 통증 감소 효과는 차이 없이 지속되었다. 시술 전과 비교하여 1주, 4 주, 8 주째 WOMAC 점수는 감소하였고 8주째까지 차이 없이 감소가 지속되었다. 골 관절염 1,2 단계 환자들에서 상당한 호전이 있었던 환자들의 비율이 골관절염 3 , 4 단계 환자들보다 1 주, 4 주, 8 주째 유의하게 많았 다 $(\mathrm{p}<0.05)$.

결론: 무릎 내측 구획 골관절염 환자에서 초음파 유도하 무릎 관절강내 경 반월상 연골 주사는 평균 8주 이상의 통증 감소 및 기능 개선 효과를 보였다. 특히 내측 구획 골관절염 1,2 단계 환자에서는 통증 감소 효과가 더 컸다.

색인단어: 무릎, 골관절염, 초음파, 주사

접수일 2019년 9월 20일 수정일 2019년 11월 4일 게재확정일 2019년 11월 18일

책임저자 왕준호

06351 , 서울시 강남구 일원로 81 , 삼성서울병원 정형외과

TEL 02-3410-3507, FAX 02-3410-0061, E-mail mdwang88@gmail.com, ORCID https://orcid.org/0000-0001-6530-795X 